\title{
Design of Janus Nanoparticles with pH-Triggered Switchable Amphiphilicity for Interfacial Applications
}

\author{
Dalin $\mathrm{Wu}^{\dagger}$ and Andrei Honciuc* ${ }^{* \dagger}$ \\ ${ }^{\dagger}$ Institute of Chemistry and Biotechnology, Zurich University of Applied Sciences, Einsiedlerstrasse 31, 8820 Waedenswil, Switzerland
}

Supporting Information

ABSTRACT: The ability of amphiphilic Janus nanoparticles (JNPs) to partition at the oil-water and air-water interfaces can be especially attractive for a plethora of new applications. Unlike molecular surfactants, the JNPs could act as "bulk-tosurface" carriers of different small molecules/actives or bulklike properties-magnetic, optic, or electric-without a dramatic effect on their ability to partition at interfaces. Here we report surfactant-free JNPs with $\mathrm{pH}$-triggered switchable amphiphilicity that could be used in such interfacial applications. The polarity balance of the JNPs can be tuned by the $\mathrm{pH}$ such that the amphiphilicity of JNPs is switched on or off at low $(\mathrm{pH}$

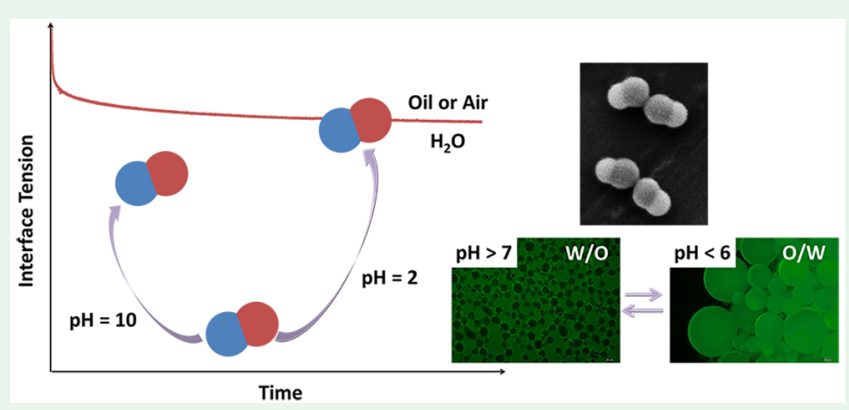
$<6.0)$ or high $(\mathrm{pH}>7.0) \mathrm{pH}$ values, respectively. When the amphiphilicity of JNPs is switched off, the interfacial activity of JNPs is comparable to that of homogeneous nanoparticles (HNPs), and when switched on, the interfacial activity is enhanced, proving that the amphiphilicity of JNPs plays a role in enhancing the interfacial activity even at scales above $100 \mathrm{~nm}$. In addition, we show that the ability to lower the interfacial tension $(\Delta \mathrm{IFT})$ is likely the most appropriate indicator to compare the interfacial activities of different particles because it does not scale with the size of the particles like the calculated activation energy $E_{a}$ or attachment energy $\Delta E$. By comparing the mentioned parameters, we conclude that the enhancement in the interfacial activity is slightly larger than the earlier theoretical predictions that only compare the $\Delta E$ values. These $\mathrm{pH}$-responsive JNPs were further applied in the generation of $\mathrm{pH}$-responsive Pickering emulsions. Upon adsorption of these JNPs at the oil-water interfaces, the particleladen interface acquires a $\mathrm{pH}$-responsiveness functionality. For example, Pickering emulsions stabilized by the above $\mathrm{pH}$ responsive JNPs undergo reversible water-in-oil (w/o) to oil-in-water $(\mathrm{o} / \mathrm{w})$ phase inversion when the aqueous phase changes from basic to acidic.

KEYWORDS: $p H$-responsive Janus nanoparticles, $p H$-triggered switchable amphiphilicity, $p H$-responsive Pickering emulsion, hinterfacial adsorption, surfactant-free polymerization

\section{INTRODUCTION}

Janus nanoparticles (JNPs) are asymmetric nanoparticles (NPs) consisting of at least two parts differing in their properties. ${ }^{1-5}$ These JNPs may find use in interfacial applications for creating ultrastable stimuli-responsive Pickering emulsions, ${ }^{6}$ ultrastable foams, ${ }^{7}$ self-assembly into supramolecular structures, ${ }^{8,9}$ etc. The concept of amphiphilic JNPs or "solid-state" amphiphiles ${ }^{10,11}$ was put forward in the 1990s by Casagrande and de Gennes, ${ }^{2,4}$ who named these after the two-faced roman god Janus, thus promoting the idea that amphiphilicity is a scalable property. This idea is of significant fundamental interest because amphiphilicity is the driving force behind the self-assembly and formation of reconfigurable materials ${ }^{12}$ and suprastructures. ${ }^{13,14}$ Further, it has been predicted that, because of their amphiphilicity, JNPs may exhibit up to a 3-fold-enhanced interfacial activity over homogeneous nanoparticles (HNPs). ${ }^{15,16}$ While the enhanced interfacial activity due to the inherent amphiphilicity of JNPs arising from the polarity contrast between two surface regions was well-acknowledged, it remained difficult to demonstrate experimentally because of the laboriousness involved in obtaining these colloids in sufficient amounts in the absence of surfactants and stabilizers. It has been reported that JNPs covered with a corona of polymer brushes, ${ }^{17}$ capping agents, ${ }^{18}$ or very soft and gel-like JNPs ${ }^{19}$ are indeed capable of spontaneous adsorption at oil-water and air-water interfaces, but there were no direct comparisons to HNPs. Therefore, it is not clear if the interfacial activity is directly attributable to the amphiphilicity of JNPs or rather may be a characteristic of the accompanying polymers or molecular surfactants involving particle deformation and spreading or corona-only interfacial adsorption. ${ }^{10,20,21}$ Recently, Hidalgo-Alvarez et al. ${ }^{22}$ provided the first direct experimental evidence that gold JNPs, half capped with polar and half with nonpolar agents, can spontaneously adsorb at oil-water or air-water interfaces with an enhanced interfacial activity compared to that uniformly capped gold HNPs. Thus, they have attributed this enhanced activity of these rather small $\sim 3.5 \mathrm{~nm}$ gold JNPs to their amphiphilicity. The aim of this work is to design JNPs capable of spontaneous interfacial

Received: December 15, 2017

Accepted: December 20, 2017

Published: December 20, 2017 
Scheme 1. Synthesis Route of pH-Responsive PDIPAEMA/P(3-TSPM) JNPs by Surfactant-Free Emulsion Polymerization and Phase Separation

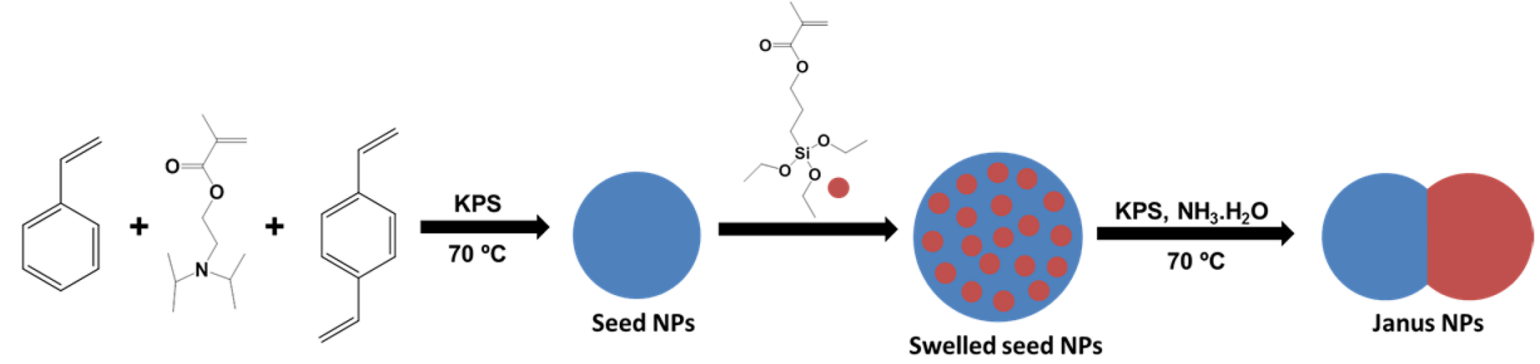

adsorption that can expand the current understanding on the role played by the amphiphilicity in enhancing the interfacial activity of JNPs at scales above $100 \mathrm{~nm}$. For this, we have designed and synthesized polystyrene-poly[2-(diisopropylamino)ethyl methacrylate]/poly[3-(triethoxysilyl)propyl methacrylate] [PS-PDIPAEMA/P(3-TSPM)] JNPs in surfactant-free conditions whose amphiphilicity can be switched on at low $\mathrm{pH}$ values $(\mathrm{pH} 2.0)$ and switched off at high $\mathrm{pH}$ values $(\mathrm{pH}>6.0)$. When the amphiphilicity is switched on, the JNPs adsorb spontaneously at the air-water, toluene-water (Tol-water), and heptanewater (Hep-water) interfaces and produce a large drop in the interfacial tension (IFT). By comparing the drop in the IFT for the JNPs with that for the HNPs with the same composition at each of the Janus lobes, we conclude that JNPs have up to a 3fold-enhanced interfacial activity. When the JNPs' amphiphilicity is switched off, the JNPs do not exhibit any interfacial activity. By adopting a simple model of the effective diffusion coefficient, we were able to calculate the activation energy barriers for the JNPs and HNPs at each interface. The HNPs show a consistently larger activation energy barrier for interfacial adsorption than the amphiphilic JNPs. In addition, the air-water interface appears to be the least "attractive" interface compared to Tol-water or Hep-water for particle adsorption.

It is important to note that the use of capping agents or surfactants during synthesis can be a spinous aspect in interfacial measurements because first they can detach with time from the particle surface and second they could mediate the particle interfacial adsorption. Therefore, in the current work, we use surfactant-free synthesis methods. ${ }^{23}$

In the presence of convection currents due to mechanical agitation, the PS-PDIPAEMA/P(3-TSPM) JNPs acquire high kinetic energy and increased bulk diffusivities, easily overcoming the interfacial adsorption energy barriers adsorbing irreversibly at the Tol-water and Hep-water interfaces. Thus, they function as highly efficient emulsifiers generating Pickering emulsions. As a side note, because of their external energy input, both HNPs and JNPs can adsorb at the interface showing interfacial activity, but their activities are difficult to compare. Upon adsorbing the amphiphilic JNPs at the oil-water interface, the particle-laden interfaces acquire an extra functionality. For example, the Pickering emulsions stabilized by the amphiphilic JNPs acquire $\mathrm{pH}$-responsiveness and the emulsion phase can be changed dynamically from oil in water $(\mathrm{o} / \mathrm{w})$ to water in oil $(\mathrm{w} / \mathrm{o})$ and vice versa by $\mathrm{pH}$ adjustment and gentle shaking. These $\mathrm{pH}$ responsive Pickering emulsions could be used in drug delivery, cosmetics applications, ${ }^{3,24,25}$ and multiphase catalysis reactions. $^{26-28}$

\section{EXPERIMENTS AND METHODS}

2.1. Materials. Styrene (Sty; >99\%), divinylbenzene (DVB; $80 \%$ ), sodium 4-vinylbenzenesulfonate $(\mathrm{NaVBS} ;>90 \%)$, potassium peroxodisulfate (KPS; >98\%), ethanol (>99\%), methyl methacrylate (MMA; $>99 \%)$, toluene (>99\%), ammonium hydroxide solution $\left(\mathrm{NH}_{4} \mathrm{OH}\right.$; 28\%), 3-(triethoxysilyl)propyl methacrylate (3-TSPM; >99\%), 2(diisopropylamino)ethyl methacrylate (DIPAEMA; >99\%), paraffin wax $\left(\mathrm{C}_{n} \mathrm{H}_{2 n+2}, n=24-36 ; \mathrm{mp} 53-57^{\circ} \mathrm{C}\right)$, and aluminum oxide $\left(\mathrm{Al}_{2} \mathrm{O}_{3}\right.$ basis; $\geq 98 \%)$ were purchased from Sigma-Aldrich. Sty, DIPAEMA, and DVB were passed through $\mathrm{Al}_{2} \mathrm{O}_{3}$ to remove the stabilizer before use. Other reagents were used as received. Ultrapure water (UPW; resistivity, $\rho$, at $298 \mathrm{~K}: 0.055 \mathrm{~S} / \mathrm{cm}^{-2}$, or $18.2 \mathrm{M} \Omega \mathrm{cm}$ ) was obtained from an Arium $611 \mathrm{VF}$ water purification system (Startorius Stedim Biotech, Aubagne, France). Toluene ( $\mathrm{Tol} ;>99 \%)$ and heptane (Hep; >99\%) were purchased from Sigma-Aldrich and used for interfacial experiments without further purification.

2.2. PS-PDIPAEMA Seed NPs and PS-PDIPAEMA/P(3-TSPM) JNP Synthesis. PS-PDIPAEMA seed NPs with $\zeta$-potential values of $\sim-50 \mathrm{mV}$ were synthesized by surfactant-free emulsion polymerization according to the procedure described in the Supporting Information (SI). The polymerization reaction was carried out under basic conditions, mainly because the monomer DIPAEMA has a $\mathrm{p} K_{\mathrm{a}}$ of $6.3^{29}$ and acidic conditions would increase its solubility in water and thus decrease its miscibility with the Sty monomer. The ratio of Sty to DIPAEMA monomer was adjusted in order to obtain solid (not gel-like) round-shaped NPs while still maintaining a good $\mathrm{pH}$-responsive behavior. To find the best candidate fulfilling the above criteria, three different seed NPs, namely, PS-PDIPAEMA-1, PS-PDIPAEMA-2, and PS-PDIPAEMA-3, were synthesized with different concentrations of the Sty monomer in the composition; the synthesis conditions are presented in Table S1. The DVB monomer was used as a cross-linker to confer JNP resistance to dissolution by organic solvents, and the amount of DVB used was kept at $1 \%$ volume. The hydrodynamic diameters of three PS-PDIPAEMA seed NPs measured by DLS increased from $90 \pm$ 21 to $149 \pm 32 \mathrm{~nm}$ at $\mathrm{pH} 7.0$ with an increase in the percentage of Sty to DIPAEMA from $0 \%$ to $50 \%$. The morphologies of PS-PDIPAEMA seed NPs are presented in Figure S1. Because PS-PDIPAEMA- 1 were too soft, only PS-PDIPAEMA-2 and PS-PDIPAEMA-3 were used as the seed NPs for further $\mathrm{pH}$-responsive JNP synthesis. PSPDIPAEMA/P(3-TSPM) JNPs were synthesized according to our previously reported procedure but by using $\mathrm{pH}$-responsive PSPDIPAEMA NPs as seed NPs in the seeded emulsion polymerization, according to Scheme 1. The detailed procedure is given in the SI. Two JNPs were finally synthesized from the PS-PDIPAEMA- 2 and -3 seed NPs (Table S2) in the same conditions. The Fourier transform infrared (FTIR) spectra of the obtained NPs and JNPs are given in Figure S2.

2.3. PS-P(3-TSPM) Core-Shell Particle Synthesis. The PS-P(3TSPM) core-shell NPs were synthesized from the same seeds by using a procedure modified from the one in the reported literature. ${ }^{30}$ The procedure was presented in the SI. The core-shell NPs were purified by centrifugation and rinsed with ethanol and UPW; the rinsing procedure was repeated three times before IFT measurement. The hydrodynamic diameter of the synthesized PS-P(3-TSPM) core-shell NPs is $220 \pm$ $53 \mathrm{~nm}$ by DLS measurement. SEM images of the obtained particles are presented in Figure S1D. 

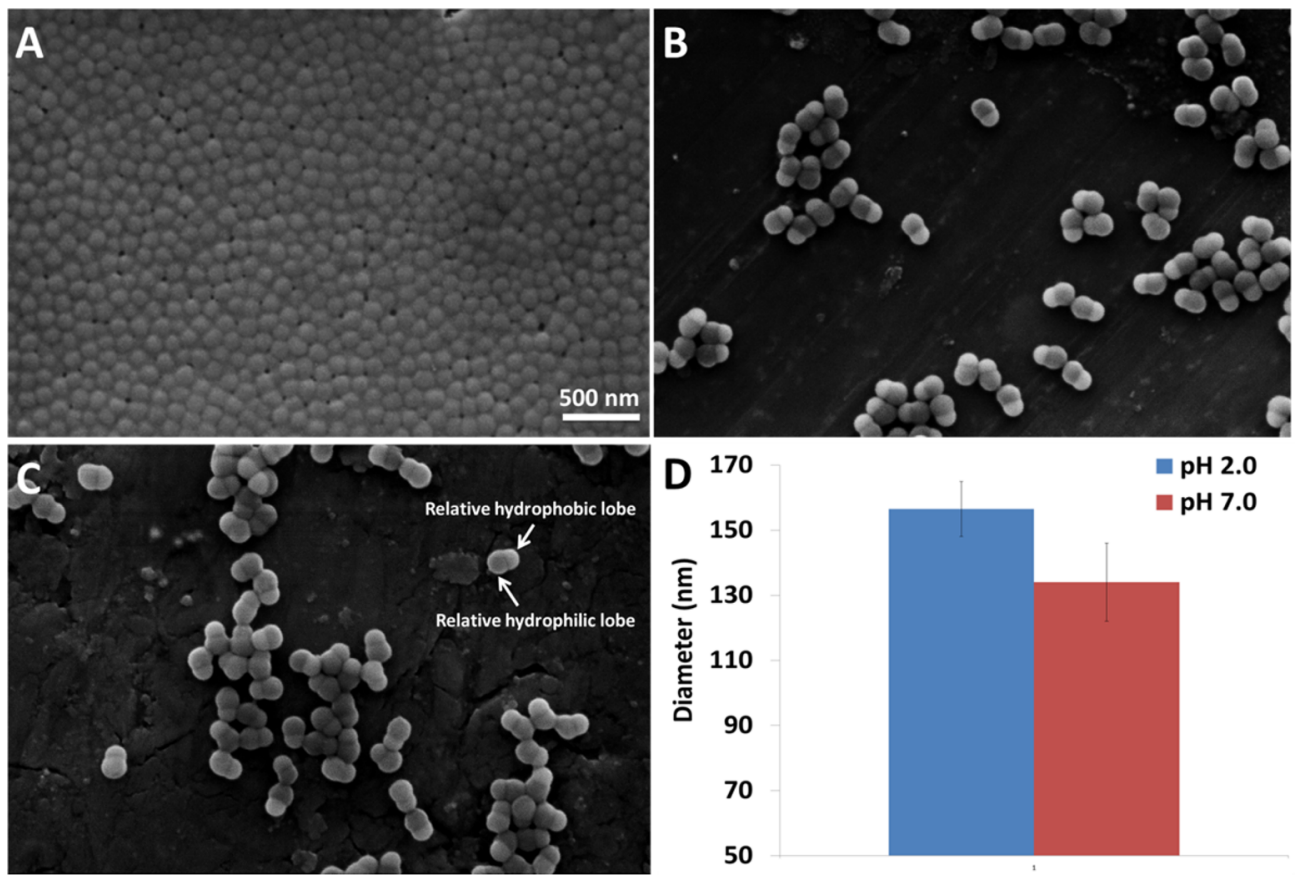

$\square \mathrm{pH} 2.0$

pH 7.0

Figure 1. Typical SEM images of synthesized NPs: (A) PS-PDIPAEMA-2 seed NPs; (B) PS-PDIPAEMA/P(3-TSPM)-1 JNPs at pH 7.0; (C) PSPDIPAEMA/P(3-TSPM)-1 JNPs at $\mathrm{pH}$ 2.0. (D) Relative diameters of the PS-PDIPAEMA lobes on JNPs at $\mathrm{pH} 2.0$ and 7.0 measured directly from the SEM images and representing the average of 30 particles. Scale bar $=500 \mathrm{~nm}$.

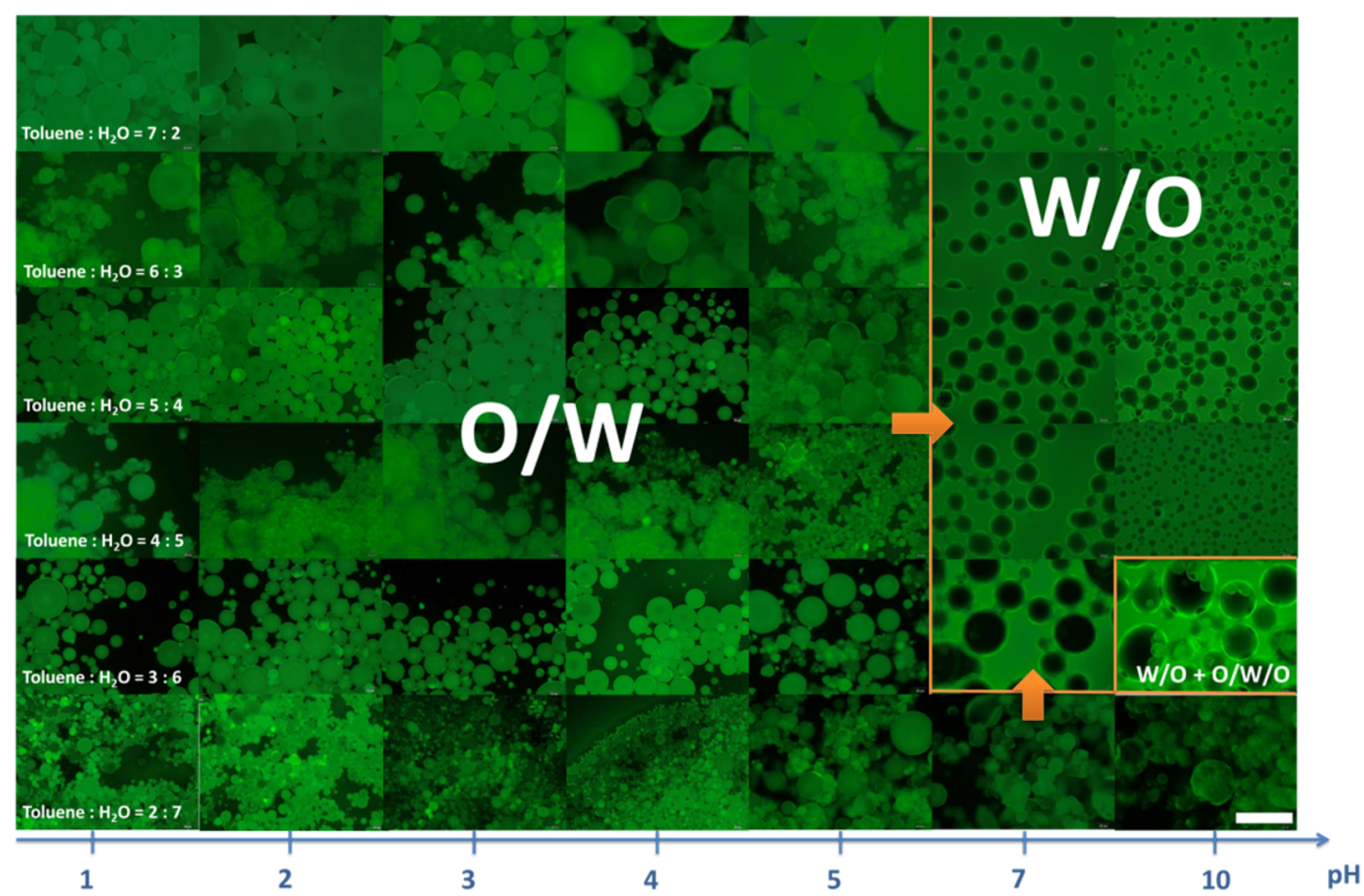

Figure 2. Formulation-composition map depicting a matrix of fluorescence microscopy snapshots relating the type of Pickering emulsion stabilized by PS-PDIPAEMA/P(3-TSPM)-1 JNPs with the Tol-water ratios and the $\mathrm{pH}$ of the aqueous phase. The snapshots were taken within 1 day after the emulsion preparation. Scale bar $=200 \mu \mathrm{m}$.

\section{RESULTS AND DISCUSSION}

3.1. PS-PDIPAEMA/P(3-TSPM) JNPs. SEM images of the obtained PS-PDIPAEMA/P(3-TSPM)-1 JNPs at $\mathrm{pH} 7.0$ are presented in Figure 1B, showing that the JNPs, obtained according to Scheme 1, have a snowman-type architecture and are clearly asymmetric compared with the starting seed NPs
(PS-PDIPAEMA-2) in Figure 1A. In Figure 1A, the hydrophobic $\mathrm{P}(3-\mathrm{TSPM})$ lobe appears brighter and the hydrophilic lobe PS-PDIPAEMA lobe appears darker; the images were acquired at normal $\mathrm{pH}$. In addition, the SEM images of PSPDIPAEMA/P(3-TSPM)-1 were also acquired (Figure 1C) after treatment of these particles at $\mathrm{pH} 2.0$, and this shows that these 
particles are very stable in acidic conditions and the snowmanlike morphology remains unaffected. The diameter of the PSPDIPAEMA-2 lobe in JNPs increases by approximately $25 \mathrm{~nm}$ (Figure 1D) with a decrease of the $\mathrm{pH}$ value from 7.0 to 2.0 , in agreement with the DLS measurements.

3.2. pH-Responsive Behavior of Seed NPs and JNPs. The tertiary amine group on PDIPAEMA becomes positively charged below pH $6.0\left(\mathrm{pK}_{\mathrm{a}}=6.3\right)$ because of protonation. ${ }^{29}$ As a result, PS-PDIPAEMA seed NPs become more hydrophilic and their diameters increase because of hydration and water intake. The measured hydrodynamic diameters of the three PSPDIPAEMA seed NPs synthesized by DLS at $\mathrm{pH} 7.0$ and 1.0 are given in Table $\mathrm{S} 1$ and Figure $\mathrm{S} 3$. The results demonstrate that the NPs' diameters are significantly larger in $\mathrm{pH} 1.0$ than in $\mathrm{pH}$ 7.0. Consequently, the PS-PDIPAEMA Janus lobe is expected to have the same behavior. Also, because of protonation of the tertiary amine, the $\zeta$-potential values of the PS-PDIPAEMA/ $\mathrm{P}$ (3-TSPM)-1 JNPs change from -75 to $+44 \mathrm{mV}$ with a decrease in the $\mathrm{pH}$ value from 11.0 to 3.0 (Figure $\mathrm{S} 4 \mathrm{~A}$ ).

PS-PDIPAEMA/P(3-TSPM)-1 JNPs were monodisperse when the $\mathrm{pH}$ was above $7.0(\zeta<-30 \mathrm{mV})$ and were aggregated when the $\mathrm{pH}$ value dropped below $7.0(-30 \mathrm{mV}<\zeta<+30 \mathrm{mV}$; Figure S4B). For the $\mathrm{pH}$ interval between 3.0 and 7.0, the JNPs formed micron-sized aggregates but redispersed again, becoming monodisperse for $\mathrm{pH}$ values below $3.0(\zeta \approx+43 \mathrm{mV}$; Figure S4B). The reversal of the $\zeta$-potential sign with the $\mathrm{pH}$ indicates that the surfaces of the JNPs are amphoteric and zwitterionic. At $\mathrm{pH}$ values greater than the $\mathrm{p} K_{\mathrm{a}}(6.3)$ value of PDIPAEMA, the negatively charged $-\mathrm{SO}_{3}{ }^{-}$groups were mostly present, while at $\mathrm{pH}$ values less than the $\mathrm{p} K_{\mathrm{a}}(6.3)$ value of the tertiary amine, the positively charged $-\mathrm{N}^{+} \mathrm{R}_{2} \mathrm{H}$ functionalities on the PSPDIPAEMA lobe predominate. In addition, when the JNPs contained a larger proportion of Sty monomer and less DIPAEMA monomer, as is the case for PS-PDIPAEMA/P(3TSPM)-2, the positively charged functional groups $-\mathrm{N}^{+} \mathrm{R}_{2} \mathrm{H}$ at $\mathrm{pH}$ values less than the $\mathrm{p} K_{\mathrm{a}}$ (6.3) value of PDIPAEMA were not sufficient to overcome the negatively charged $\mathrm{SO}_{3}{ }^{-}$and thus the JNPs' surfaces stay in the negatively charged region throughout the entire $\mathrm{pH}$ range and aggregated for $-30 \mathrm{mV}<\zeta<+30 \mathrm{mV}$ (Figure S4C,D). Therefore, PS-PDIPAEMA/P(3-TSPM)-2 JNPs were excluded from further emulsification experiments and interface activity studies.

3.3. pH-Responsive Pickering Emulsions Stabilized by the JNPs. The PS-PDIPAEMA/P(3-TSPM)-1 pH-responsive JNPs were further employed to emulsify the mixture of toluene and water. The concentration of the JNPs was kept constant per emulsion volume, $\sim 2.22 \mathrm{mg} / \mathrm{mL}$. The emulsification results, shown in Figure 2, are represented as a formulationcomposition map depicting a matrix of fluorescence microscopy snapshots relating the type of Pickering emulsion formed with the Tol-water ratios and the $\mathrm{pH}$ of the aqueous phase. The hydrophobic dye Hostasol Yellow 3G was added to the Tol phase to facilitate identification of the Pickering emulsion phase with the fluorescence microscope; i.e., the phase appearing brighter is the oil, and that appearing darker is the aqueous phase. In this map, a static transitional emulsion phase inversion from $\mathrm{o} / \mathrm{w}$ to $\mathrm{w} / \mathrm{o}$ can be observed, and this is indicated by a horizontal arrow in Figure 2. Namely, o/w emulsions (dispersed-phase bright green) were formed at $\mathrm{pH}$ values below 6 (Tol-water ratios from $7: 2$ to $2: 7$ ), and the $\mathrm{w} / \mathrm{o}$ emulsion formed in the $\mathrm{pH}$ value above 6.0 (Tol-water ratios from $7: 2$ to $3: 6$ ). In a different representation in Figure 2, instead of the $\mathrm{pH}$, one could consider the impact of the degree of protonation $\alpha$ (from 0 to 1 ), of the
$-\mathrm{N}^{+} \mathrm{R}_{2} \mathrm{H}$ on the JNPs' surfaces and on the type of Pickering emulsion obtained. In the ideal case, in which a single functional group is present at the particle's surface, namely, $-\mathrm{N}^{+} \mathrm{R}_{2} \mathrm{H}, \alpha$ can be determined by calculating the surface charge density $\sigma$ from the value of the $\zeta$ potential at each $\mathrm{pH}$ value shown in Figure S4. However, in the current case, such calculations are complicated by the existence of the negatively charged functional groups $\left(\mathrm{SO}_{3}{ }^{-}\right.$from the NaVBS monomer and $\mathrm{SO}_{4}{ }^{-}$groups inserted by the radical initiator KPS) on both Janus lobes, as reflected in the highly negative $\zeta$-potential values at high $\mathrm{pH}$. When the $\mathrm{pH}$ value decreases from 10.0 to 1.0 , the PS-PDIPAEMA lobe gradually changes from an unprotonated to a protonated state. Correspondingly, the $\zeta$-potential values of the JNPs are given, on average, by the ratio of the negatively charged functional groups on the surface of both lobes to the positive functional groups from the PS-PDIPAEMA lobe. Therefore, we feel the calculated $\alpha$ values from the $\zeta$ potentials would not be accurate in this case. As a result, only the impact of the $\mathrm{pH}$ values of the solution was considered in Figure 2 to describe the characteristics of the Pickering emulsion.

The digital images of creaming of the $\mathrm{o} / \mathrm{w}$ emulsion (Figure S5) in $\mathrm{pH}<6.0$ ( Tol-water ratios from $7: 2$ to $2: 7$ ) and settling down of the $\mathrm{w} / \mathrm{o}$ emulsions in $\mathrm{pH}>6.0$ ( Tol-water ratios from $7: 2$ to $3: 6)$ are also indicative of the emulsion phase. The $o / w$ emulsions cream up over time because of the lower density of the oil droplets formed, and the w/o emulsions settle down because of the higher density of the water droplets; this could be used to identify the emulsion type. Both Pickering emulsion types were stable toward coalescence for at least 7 months of observation time.

Here, we emphasize that, at fixed Tol-water ratios, a transitional phase inversion from $\mathrm{w} / \mathrm{o}$ to $\mathrm{o} / \mathrm{w}$ due to a $\mathrm{pH}$ change may only be induced by an increased polarity of the stabilizing particles according to the Finkel and Bancroft rules. $^{1,31,32}$ In other words, if the surfaces of the JNPs are polar enough and JNP adhesion to the water phase is stronger than that to the oil, then $\mathrm{o} / \mathrm{w}$ emulsions are formed; vice versa, if the surfaces of the JNPs are nonpolar and have a stronger adhesion to the oil phase than to water, then $\mathrm{w} / \mathrm{o}$ emulsions are obtained. ${ }^{1}$ Because our PS-PDIPAEMA/P(3-TSPM)-1 JNPs are $\mathrm{pH}$ responsive, their overall polarity, and thus affinity to water or to the oil phase, can be effectively controlled by the $\mathrm{pH}$ values of the aqueous phase. The mechanisms responsible for switching the polarity and affinity of the JNPs between the water and oil phases can be explained by protonation and deprotonation of the tertiary amine groups on the surface of the PS-PDIPAEMA lobe, as was already discussed. Clearly, protonation of the tertiary amine groups greatly affects the polarity contrast between the Janus lobes and thus the amphiphilicity of the JNPs. A subject of further investigation is the impact of the relative size between the hydrophilic and hydrophobic regions on these JNPs on the Pickering emulsion properties. We hypothesize that tuning the relative sizes of the Janus lobes may greatly affect the emulsion phase inversion with the $\mathrm{pH}$ but also the curvature of the emulsion droplets due to the immersion depth of the JNPs in one phase or the other. Qualitatively, the oil droplet size in the o/w emulsions increases with an increase in the $\mathrm{pH}$ from 1.0 to 6.0 , as shown in Figure 2. The reason for this behavior is that, as the JNPs become less and less polar/hydrophilic, at $\mathrm{pH}$ values closer to 6.0, their immersion depth into the water phase becomes smaller and, subsequently, the curvature of the droplets becomes smaller; i.e., the oil droplets are larger. Immediately after the phase inversion, the size of the water droplets in the w/o 

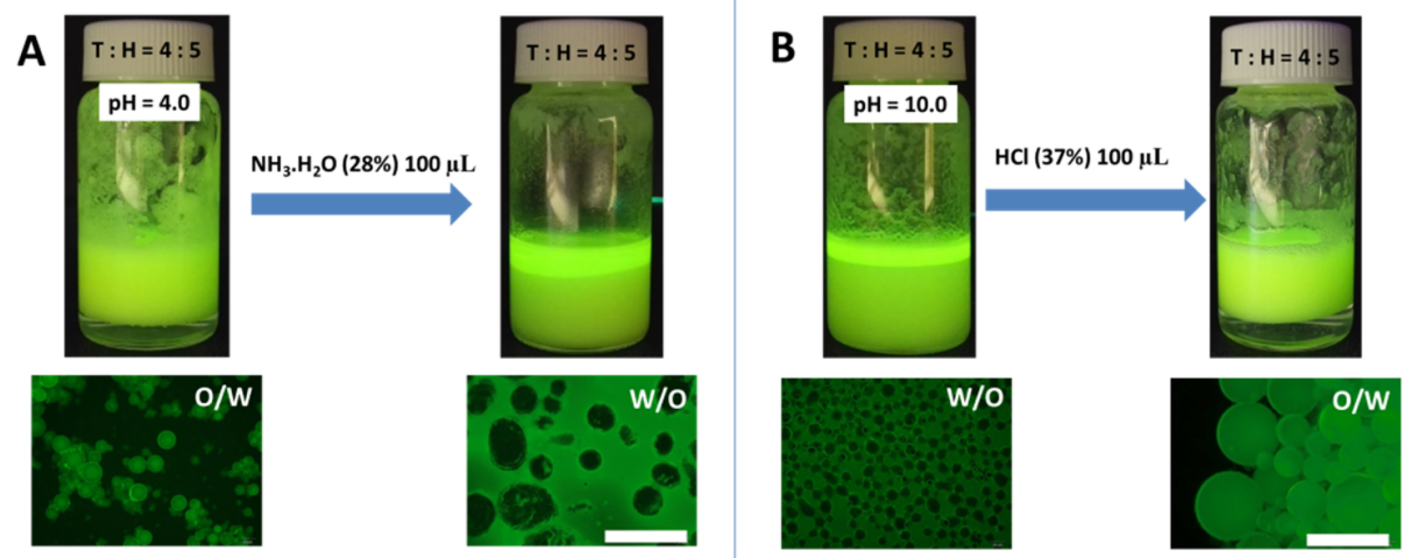

Figure 3. Dynamic Pickering emulsion phase inversion with the $\mathrm{pH}$ : (A) as-prepared o/w Pickering emulsion (Tol-water $=4: 5 \mathrm{ratio}$; $\mathrm{pH} 4.0)$ changing to w/o after the addition of $100 \mu \mathrm{L}$ of $\mathrm{NH}_{4} \mathrm{OH}(28 \%)$; (B) as-prepared w/o Pickering emulsion (Tol-water $=4: 5$ ratio, $\left.\mathrm{pH} 10.0\right)$ changing to o/w after the addition of $100 \mu \mathrm{L}$ of $\mathrm{HCl}(38 \%)$. On the top are photographs of the vials containing the Pickering emulsions, with $0.1 \%$ hydrophobic dye, and on the bottom are the fluorescence microscopy images showing the corresponding Pickering emulsion type (scale bar $=200 \mu \mathrm{m}$ ).

emulsions at $\mathrm{pH}>6.0$ become smaller, and their curvature increases; this is due to an increase in the immersion depth of the JNPs into the oil phase, as their surface becomes more and more hydrophobic with increasing $\mathrm{pH}$.

On the other hand, a catastrophic phase transition from o/w to w/o could be observed at $\mathrm{pH}>6.0$ between Tol-water $=2: 7$ and Tol-water $=3: 6$, as depicted in Figure 2 by the vertical arrow. The catastrophic phase inversion occurs at a Tol-water ratio well below that of $1: 1$, which also indicates a larger affinity of JNPs to the oil phase at $\mathrm{pH}$ values above 6.0.

While many HNPs and JNPs stabilizing the Pickering emulsion are formed by an external energy input such as ultrasonication $^{1}$ or high-speed homogenization, ${ }^{10}$ it was surprising that, in the current case, the formation of the Tolwater Pickering emulsion required only a minimum energy input such as gentle handshaking. This empirical observation indicates that the PS-PDIPAEMA/P(3-TSPM)-1 JNPs already have a high interfacial activity. Qualitatively, if a high energy input is required for Pickering emulsion formation, the particles must overcome a large activation energy barrier for interfacial attachment. $^{1}$

The observed static transitional phase inversion from $\mathrm{o} / \mathrm{w}$ to w/o in Figure 2 assumes that the Pickering emulsions are generated in stable conditions; that is, the concentrations of the JNPs is constant and the emulsions are each time-prepared for the corresponding $\mathrm{pH}$ value. It was also possible to change the type of formed Pickering emulsion just by changing the $\mathrm{pH}$ value of an already formed Pickering emulsion, and this process is known as a dynamic transitional emulsion inversion. ${ }^{33}$ For this purpose, $100 \mu \mathrm{L}$ of $\mathrm{NH}_{4} \mathrm{OH}(28 \%)$ was added to an o/w Pickering emulsion previously prepared for a Tol-water $=4: 5$ ratio at $\mathrm{pH} 4.0$, and after gentle shaking, the Pickering emulsion phase changed to $\mathrm{w} / \mathrm{o}$. The corresponding fluorescence microscopy images and photographs of the vials are presented in Figure 3A (left), with the o/w Pickering emulsion as prepared and the w/o Pickering emulsion after the addition of base. Oppositely, after $100 \mu \mathrm{L}$ of $\mathrm{HCl}$ (38\%) was added to a w/o Pickering emulsion previously prepared for Tol-water $=4: 5$ at $\mathrm{pH} 10.0$ and gentle shaking, the Pickering emulsion changed to $\mathrm{o} / \mathrm{w}$. Also, for this case, the corresponding fluorescence microscopy images and photographs of the vials are presented in Figure 3B (right) with the w/o Pickering emulsion as prepared and the $\mathrm{o} / \mathrm{w}$ Pickering emulsion after the addition of acid. The volume of the acid and base added to the vials containing the Pickering emulsion was negligible to induce a change of the emulsion type by changing the Tol-water ratio due to an increase in the ionic strength. In order to test if the emulsion phase can be changed by the ionic strength rather than the $\mathrm{pH}$, we added a $\mathrm{NaCl}$ electrolyte and observed no effect on the Pickering emulsion type; see the discussion in the SI and the results in Figure S6.

As a control, we also prepared several Pickering emulsions stabilized only by PS-PDIPAEMA-2 seed NPs with the same concentrations as JNPs. The fluorescence microscopy images (Figure S7) show that the corresponding Pickering emulsion can also switch phases with the $\mathrm{pH}$ below and above the $\mathrm{p} K_{\mathrm{a}}$ value of PDIPAEMA (Figure S7A,B) but less efficiently. While the JNPstabilized Pickering emulsions show a phase-switching ability at high Tol-water ratios up to 7:2, the Pickering emulsions stabilized by PS-PDIPAEMA-2 seed NPs do not show this ability (Figure S7C,D). In addition, the o/w Pickering emulsion morphologies are not as good as the ones stabilized by the corresponding JNPs; the oil droplets appear less defined.

The above result demonstrates that Pickering emulsions having the Tol-water interface populated with PS-PDIPAE$\mathrm{MA} / \mathrm{P}$ (3-TSPM)-1 JNPs becomes $\mathrm{pH}$-responsive. It is important to note that the JNPs used here are surfactant-free; the presence of a surfactant would substantially interfere and influence not only both the Pickering emulsion type and the interfacial activity but also the surface properties of the JNPs, such as the polarity contrast between lobes and amphiphilicity. We strongly believe that in the presence of surfactants or stabilizers the interfacial properties of the NP-populated interfaces are difficult to control. Previously, $\mathrm{Tu}$ and Lee ${ }^{10}$ have also reported $\mathrm{pH}$-responsive Pickering emulsions stabilized by large $\sim 1 \mu \mathrm{m}$ JNPs but have a $\mathrm{pH}$-switching behavior opposite from those reported here. In their case, to observe the emulsion phase inversion after changing the $\mathrm{pH}$, vortex shaking was applied. The advantage of the smaller JNPs used here $\sim 200 \mathrm{~nm}$ is that these smaller particles, in addition to their capability of spontaneously adsorbing at the interface as discussed next, are more efficient emulsifiers and only require low energy input 

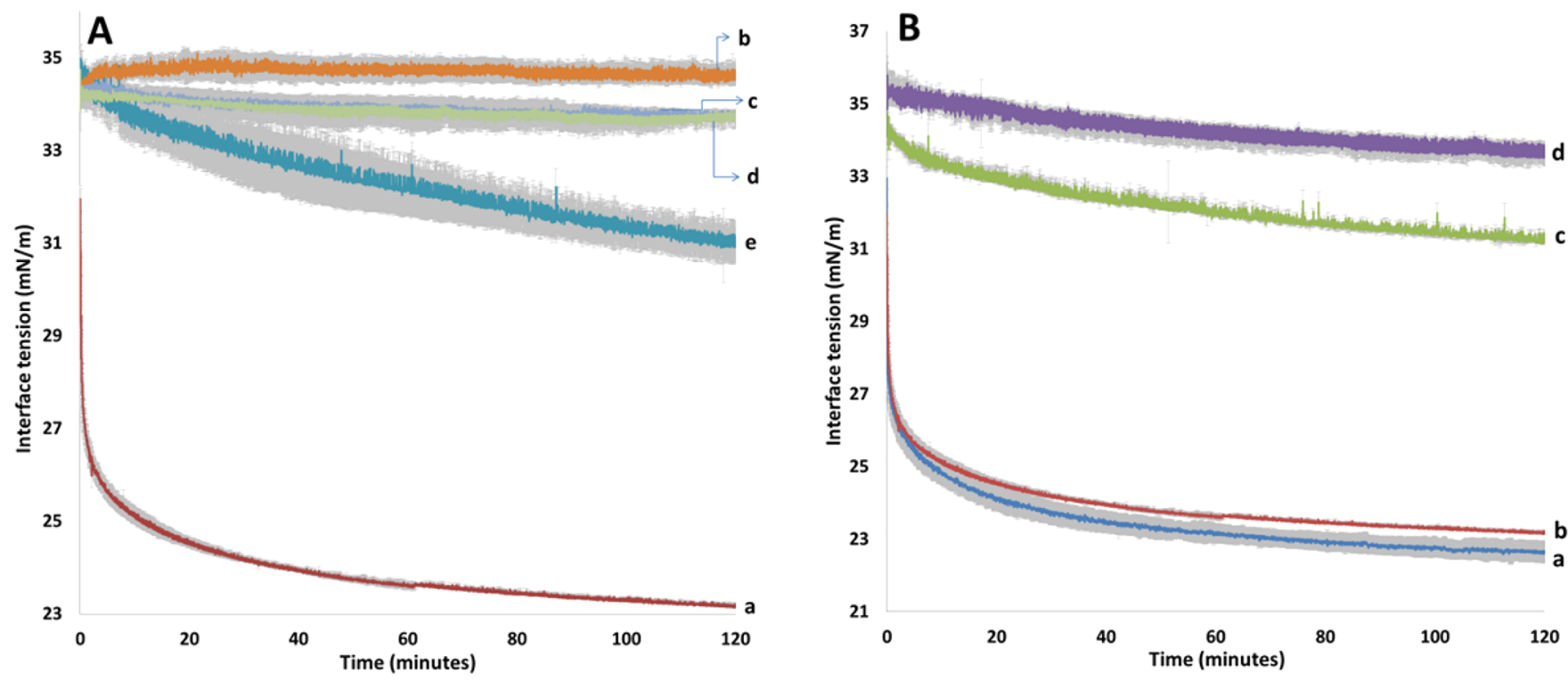

Figure 4. IFT versus time curves of the Tol-water interface in the presence of NPs and JNPs. (A) IFT evolution at different $\mathrm{pH}$ values. The NP concentration was kept constant at $10 \mathrm{mg} / \mathrm{mL}$ for PS-PDIPAEMA/P(3-TSPM)-1 JNPs at (a) pH 2.0, (b) pH 6.0, and (c) pH 10.0, for PS-P(3-TSPM) core-shell NPs at (d) $\mathrm{pH}$ 2.0, and for PS-PDIPAEMA-2 NPs at (e) $\mathrm{pH}$ 2.0. (B) Evolution of the IFT with the concentration of PS-PDIPAEMA/P(3TSPM)-1 JNPs at pH 2.0: (a) $20 \mathrm{mg} / \mathrm{mL}$; (b) $10 \mathrm{mg} / \mathrm{mL}$; (c) $1 \mathrm{mg} / \mathrm{mL}$; (d) $0.1 \mathrm{mg} / \mathrm{mL}$. Each data point is the average of three independent measurements, and the error bars in gray represent the standard deviation. The data were acquired at $21^{\circ} \mathrm{C}$.

(gentle shaking). Such pH-responsive Pickering emulsions could be employed in encapsulations and triggered release applications.

3.4. pH-Switchable Amphiphilicity and Interfacial Activity of JNPs. The inherent amphiphilicity of JNPs stems from a polarity contrast between the surfaces of the two lobes. A large amphiphilicity of the JNPs is desirable because it can increase their interfacial activity by up to 3 times larger than their corresponding HNPs with the same surface properties, as shown by Fletcher and Binks, ${ }^{34}$ at least at the oil-water interface and potentially much larger at the air-water interface. Next, we are testing this hypothesis by measuring the IFT of the JNPs at both the oil-water and air-water interfaces.

From the emulsification data, we have shown that the PSPDIPAEMA/P(3-TSPM)-1 JNPs have two polarity states. At $\mathrm{pH}$ $<6.0$, they have a stronger affinity to water than to oil, while at $\mathrm{pH}$ $>6.0$, they have a stronger affinity to oil. We attribute this overall behavior to the protonated state of the PS-PDIPAEMA lobe in the former case and the deprotonated state in the latter case. At the same time, the P(3-TSPM) lobe remains largely neutral in these $\mathrm{pH}$ values, as will be discussed later. As a result, the amphiphilic balance, which is the expression of the polarity contrast between the lobes of JNPs, is expected to change dramatically with the $\mathrm{pH}$ values.

We have first measured the IFT of the Tol-water interface in the presence of PS-PDIPAEMA/P(3-TSPM)-1 JNPs (10 mg/ $\mathrm{mL}$ ) at three different $\mathrm{pH}$ values: $2.0,6.0$, and 10.0. The results of these measurements are presented in Figure 4A. The measurements for $\mathrm{pH} 2.0$ clearly show that the Tol-water IFT decreases from the initial $35 \mathrm{mN} / \mathrm{m}$ at $t=0 \mathrm{~s}$ to $\sim 23 \mathrm{mN} / \mathrm{m}$ at $t \sim 120 \mathrm{~min}$ (Figure 4A-a). Therefore, the drop of IFT in this time interval was $\Delta$ IFT $\sim 12 \mathrm{mN} / \mathrm{m}$. In contrast, no significant IFT decrease was observed for $\mathrm{pH} 6.0$ and 10.0, $\Delta \mathrm{IFT} \approx 0 \mathrm{mN} / \mathrm{m}$ (Figure 4Ab,A-c). This clearly indicates that the enhanced interfacial activity of the PS-PDIPAEMA/P(3-TSPM)-1 JNPs at $\mathrm{pH} 2.0$ is due to protonation of the PS-PDIPAEMA lobe. Further, we compared the interfacial activity of the JNPs with that of the HNPs with the same material composition and size corresponding to each JNP lobe, namely, the seed PS-PDIPAEMA-2 NPs and the PS-P(3TSPM) core-shell HNPs at $\mathrm{pH} 2.0$ still with a concentration of $10 \mathrm{mg} / \mathrm{mL}$. The PS-P(3-TSPM) core-shell HNPs exhibit no interfacial activity (Figure 4A-d). In contrast, the seed PSPDIPAEMA-2 NPs do exhibit interfacial activity (Figure 4A-e), with the Tol-water IFT value decreasing from the initial $35 \mathrm{mN} /$ $\mathrm{m}$ to $31 \mathrm{mN} / \mathrm{m}$ at $t \sim 120 \mathrm{~min}$ and $\Delta \mathrm{IFT} \sim 4 \mathrm{mN} / \mathrm{m}$. By comparing the absolute $\Delta$ IFT drop in both cases, we can indeed conclude that the interfacial activity is roughly three times higher for the JNPs than the HNPs, and this can only be attributed to their amphiphilicity, as predicted by Binks and Fletcher. ${ }^{34}$

It is now instructive to discuss the reasons for the spontaneous adsorption of the PS-PDIPAEMA-2 HNPs at the Tol-water interface at $\mathrm{pH} 2.0$, while no activity could be observed for the PS-P(3-TSPM) core-shell HNPs in the same conditions. It has been reported that soft particles may have stronger interfacial activity than hard particles, ${ }^{20,21}$ which could also explain the situation reported here. The change in the PS-PDIPAEMA-2 diameter from $\mathrm{pH} 7.0$ to 1.0 is approximately $86 \mathrm{~nm}$, as measured by DLS (Table S1). This change in the diameter, due to water intake, as a consequence of hydration of the charged groups, corresponds to a water volume fraction $x_{\text {water }}=\frac{R_{\mathrm{pH} 2}{ }^{3}-R_{\mathrm{pH}} 7^{3}}{R_{\mathrm{pH} 2}{ }^{3}}=0.84$ at $\mathrm{pH} 2.0$, assuming that at $\mathrm{pH}$ 7.0 the polymer fraction is $x_{\text {polymer }} \cong 1$, a strong indication of softening of the NPs. This is in agreement with the results of Destribats et al., ${ }^{35,36}$ which concluded that the deformable gellike particles are the most efficient stabilizers of Pickering emulsions; this was done by systematically monitoring the deformability of neutral PNIPAM and P(NIPAM-co-AA) with cross-linking density and $\mathrm{pH}$ value changes, respectively. On the other hand, the PS-P(3-TSPM) core-shell HNPs are rigid because of the presence of a high degree of cross-linking bridges, -SiOSi- (Figure S2). However, despite some evidence, spontaneous adsorption of the NPs at the oil-water and airwater interfaces may still not be readily attributable to the particle softness. For example, earlier reports on lightly cross-linked 
Table 1. Summary of the Results of the IFT Measurements for All of the NPs Tested in Different pH Conditions at the Same Concentration $(10 \mathrm{mg} / \mathrm{mL})$ and the Corresponding Calculated Energy of Attachment at the Tol-Water, Hep-Water, and AirWater Interfaces

\begin{tabular}{|c|c|c|c|c|c|c|c|c|c|c|c|c|c|}
\hline \multirow[b]{2}{*}{ particle } & \multirow[b]{2}{*}{$\mathrm{pH}$} & \multicolumn{4}{|c|}{ Tol-water interface } & \multicolumn{4}{|c|}{ Hep-water interface } & \multicolumn{4}{|c|}{ air-water interface } \\
\hline & & $0 \mathrm{~min}$ & $120 \mathrm{~min}$ & $\begin{array}{c}\Delta \mathrm{IFT} \\
(\mathrm{mN} / \\
\mathrm{m})\end{array}$ & $\Delta E(\mathrm{kT})$ & $0 \mathrm{~min}$ & $120 \mathrm{~min}$ & $\begin{array}{c}\mathrm{IFT} \\
(\mathrm{mN} / \\
\mathrm{m})\end{array}$ & $\Delta E(\mathrm{kT})$ & $0 \mathrm{~min}$ & $20 \mathrm{~min}$ & $\begin{array}{c}\Delta \mathrm{IFT} \\
(\mathrm{mN} / \\
\mathrm{m})\end{array}$ & $\Delta E(\mathrm{kT})$ \\
\hline JNPs & 2.0 & 34.9 & 23.2 & 11.7 & $-2.2 \times 10^{5}$ & 50.2 & 34.9 & 15.3 & $-2.9 \times 10^{5}$ & 72.6 & 68.8 & 3.8 & $-7.2 \times 10^{4}$ \\
\hline JNPs & 6.0 & 34.9 & 34.9 & 0.0 & 0.0 & 50.2 & 47 & 3.2 & $-6.0 \times 10^{4}$ & 72.6 & 72.6 & 0.0 & 0 \\
\hline JNPs & 10.0 & 34.9 & 34.9 & 0.0 & 0.0 & 50.2 & 45.5 & 4.7 & $-8.9 \times 10^{4}$ & 72.6 & 72.6 & 0.0 & 0 \\
\hline PS-PDIPAEMA-2 & 2.0 & 34.9 & 31.0 & 4.0 & $-3.0 \times 10^{4}$ & 50.2 & 41.1 & 9.1 & $-6.9 \times 10^{4}$ & 72.6 & 69.9 & 2.7 & $-2.0 \times 10^{4}$ \\
\hline P(3-TSPM) & 2.0 & 34.9 & 34.9 & 0.0 & 0 & 50.2 & & & 0 & & & & \\
\hline
\end{tabular}
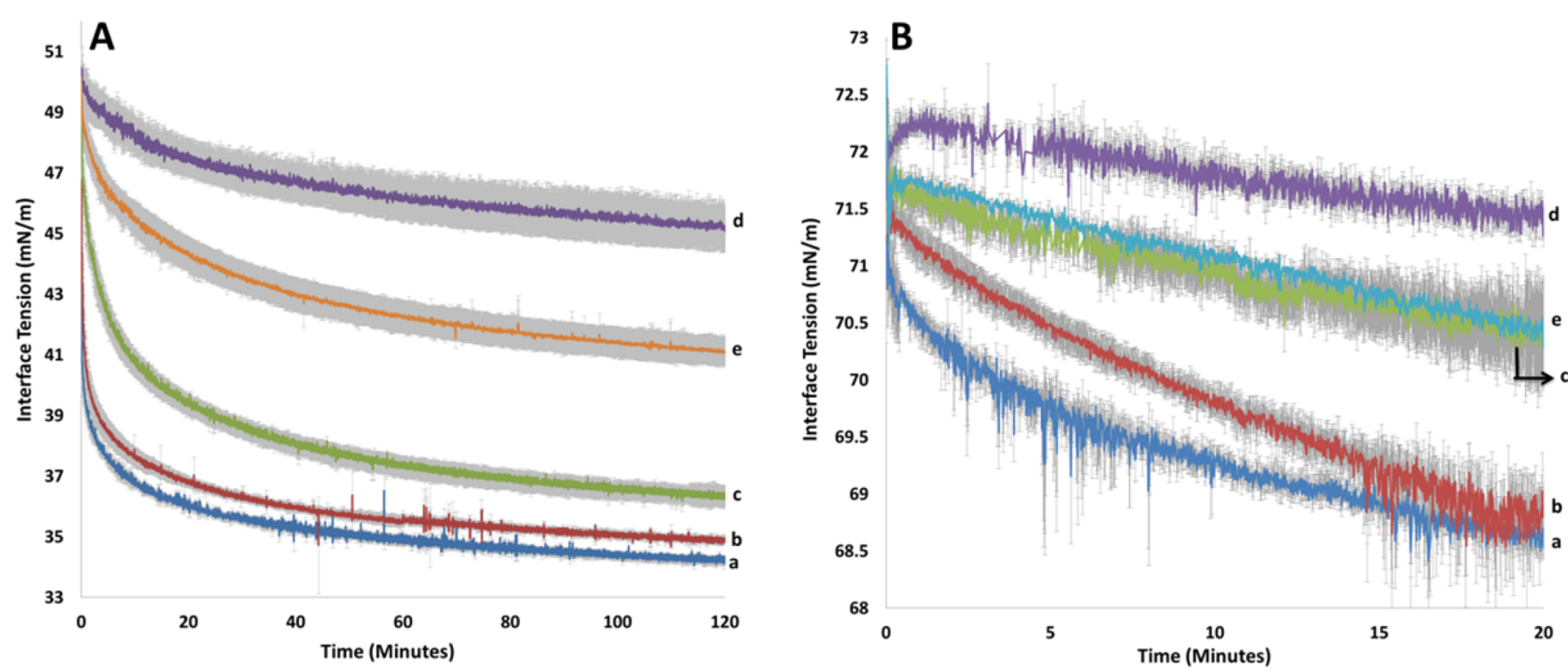

Figure 5. IFT curves of the PS-PDIPAEMA/P(3-TSPM)-1 JNPs and PS-PDIPAEMA-2 HNPs at the (A) Hep-water and (B) air-water interfaces with time. (A) IFT evolution, at $\mathrm{pH} 2.0$, as a function of the JNP concentrations of (a) 20, (b) 10, (c) 1 , and (d) $0.1 \mathrm{mg} / \mathrm{mL}$ and of a HNP concentration of (e) $10 \mathrm{mg} / \mathrm{mL}$. (B) IFT evolution, at $\mathrm{pH} 2.0$, as a function of the JNP concentrations of (a) 20, (b) 10, (c) 1 , and (d) $0.1 \mathrm{mg} / \mathrm{mL}$ and of a HNP concentration of $(\mathrm{e}) 10 \mathrm{mg} / \mathrm{mL}$. Each data point is the average of three independent measurements, and the error bars in gray represent the standard deviation. The data were acquired at $21^{\circ} \mathrm{C}$.

poly(4-vinylpyridine) $/ \mathrm{SiO}_{2}$ composite particles employed in Pickering emulsion show that $\mathrm{pH}$-triggered swelling and softening deactivated the particles' interfacial activity at the dodecane-water interface; in other words, the particles did not function as stabilizers in the highly swollen state. ${ }^{37}$

It is important to note the fundamental difference between the emulsification experiments and dynamic IFT measurements; in the former case, interfacial adsorption is caused by increased NP collisions with the interface due to mechanical energy input, and in the latter case, there is spontaneous NP adsorption in convection-free conditions. It has also been argued ${ }^{38}$ in the community whether the electrostatic interactions between the liquid-liquid and air-water interfaces that carry negative charge $^{39}$ and the colloidal particles could play a role in interfacial adsorption. In such cases, the positively charged surfactant-free particles adsorbed fast at the negatively charged air-water interface, while the negatively charged ones were much slower. ${ }^{40}$ Along these lines, Dugyala et al. ${ }^{41}$ modeled the adsorption of negatively charged particles by applying the Derjaguin-LandauVerwey-Overbeek theory, while the index-matching criterion was used by Garbin et al. ${ }^{42}$ and also by us in a previous report ${ }^{1}$ to establish if a NP can spontaneously adsorb at the air-water and oil-water interfaces, assuming that the dispersive van der Waals interaction is dominant. Therefore, a unified view of the mechanism of spontaneous particle adsorption and attachment at the oil-water and air-liquid interfaces in the absence of convection at interfaces is still pending. Here we hypothesize that both the positive charge of PS-PDIPAEMA-2 at low $\mathrm{pH}$ and the softness could potentially play a role in the lowering of the IFT.

By comparing the $\triangle$ IFT of the JNPs with that of the HNPs (with the same composition as each of the Janus lobes; Table 1), it can be clearly seen that the JNPs have the largest interfacial activity by a factor of 3 . This is surprising, and considering that the PS-P(3-TSPM) core-shell HNPs have no interfacial activity, one could have assumed that the JNPs would have an intermediate interfacial activity between no activity and that exhibited by PS-PDIPAEMA-2. We therefore emphasize again that the enhanced interfacial activity observed for the PSPDIPAEMA/P(3-TSPM)-1 JNPs can only arise as a consequence of their amphiphilicty, in agreement with the theoretical conclusions of Binks and Fletcher ${ }^{34}$ and the experiments of Glaser et al. ${ }^{43}$ and Hidalgo-Alvarez et al. ${ }^{22}$

The bulk particle concentration can influence the magnitude of $\triangle$ IFT. Therefore, we measured the drop in the IFT with the concentration at the Tol-water interface in the presence of PSPDIPAEMA/P(3-TSPM)-1 JNPs at $\mathrm{pH}$ 2.0. The results of such measurements are presented in Figure 4B for four different JNP concentrations: $0.1,1,10$, and $20 \mathrm{mg} / \mathrm{mL}$. The concentration of 
$10 \mathrm{mg} / \mathrm{mL}$ appears to be the threshold above which the IFT remains roughly constant. One could compare this with the critical micelle concentration observed for the surfactants. It can also be observed that the adsorption of JNPs at the Tol-water interface becomes faster with an increase in the JNP concentration. At concentrations of $10 \mathrm{mg} / \mathrm{mL}$ and above, it could be considered that the interface is saturated with JNPs, and no further adsorption occurs.

Dinsmore et al. ${ }^{44}$ has taken the plateau value of the minimum IFT achieved, $\gamma_{\mathrm{p}}$, due to the adsorbing particles and assumed that the interface was fully saturated, i.e., the packing parameter $\eta=$ 0.91. On the basis of these considerations, they proposed a straightforward way to calculate the interfacial attachment energy $\Delta E$ using

$$
\Delta E=-\left(\gamma_{0}-\gamma_{p}\right) \pi R^{2} / \eta
$$

where $\gamma_{0}$ is the IFT for the initial concentration of particles adsorbed at the interface and $R$ is the radius of the particles. Analyzing the dynamic IFT measurement curves in Figure 4 for the PS-PDIPAEMA/P(3-TSPM)-1 JNPs, we obtain the initial IFT $\gamma_{0}=35 \mathrm{mN} / \mathrm{m}$ at $t=0 \mathrm{~s}$ corresponding to that of the pure Tol-water interface, which implies that no particles have adsorbed at this time. Here, we emphasize that this initial value of the IFT value is very important and can be used as a quality control or proof that the measurement was performed in surfactant-free conditions. In other words, if impurities or surfactants were present in the sample, because of their extremely fast interfacial adsorption kinetics, on the order of milliseconds, the initial IFT values in the pendant-drop method (with $\sim 0.5-1$ $\mathrm{s}$ sampling rates) would appear to be significantly lower than that of the pure Tol-water interface at $t=0 \mathrm{~s}$. Therefore, great care must be taken to ensure that no impurities or surfactant capping agents are present that could interfere with such measurements. All of the curves converge to an initial value of $35 \mathrm{mN} / \mathrm{m}$ and decrease with time due to the slow adsorption of NPs at interfaces. For the curve in Figure 4A-a, the minimum value of the IFT after 120 min measurement time was $\gamma_{\mathrm{p}} \sim 23 \mathrm{mN} / \mathrm{m}$. Therefore, the calculated energy of attachment $\Delta E$ using eq 1 for the JNPs at the Tol-water interface at $\mathrm{pH} 2.0$ with a concentration of $10 \mathrm{mg} / \mathrm{mL}$ was $-2.2 \times 10^{5} \mathrm{kT}$, which is expected for such large particles because this scales with $R^{2}$. The magnitude of this latter value is the largest compared to the HNPs in the same conditions (Table 1).

Similarly, we have performed dynamic IFT measurements at the Hep-water interface with JNP concentrations at $\mathrm{pH} 2.0$. The results are presented in Figure 5A for four different JNP concentrations of $0.1,1,10$, and $20 \mathrm{mg} / \mathrm{mL}$. The concentration threshold above which the IFT plateau value $\gamma_{\mathrm{p}}$ remains the same was $10 \mathrm{mg} / \mathrm{mL}$. After a quick comparison of the curves in Figures $4 \mathrm{~B}$ and $5 \mathrm{~A}$, it appears that adsorption of the PS-PDIPAEMA/ $\mathrm{P}$ (3-TSPM)-1 JNPs at the Hep-water interface is faster than adsorption at the Tol-water interface for the same JNP concentration. For the curve in Figure 5A, the IFT at $t=0 \mathrm{~s}$ was $\gamma_{0}=50.2 \mathrm{mN} / \mathrm{m}$, and at $t=120 \mathrm{~min}$, the IFT was $\gamma_{\mathrm{p}}=39.9$ $\mathrm{mN} / \mathrm{m}$, with a corresponding attachment energy of $-2.9 \times 10^{5}$ $\mathrm{kT}$, which is larger in magnitude than that at the Tol-water interface, $-2.2 \times 10^{5} \mathrm{kT}$. The PS-PDIPAEMA-2 HNPs also showed interfacial activity at the Hep-water interface at $\mathrm{pH} 2.0$ (Figure 5A-e), and their energy of attachment was $-6.9 \times 10^{-4}$ $\mathrm{kT}$, lower in magnitude than that of the PS-PDIPAEMA/P(3TSPM)-1 JNPs. Similar calculations were performed for the PS-
PDIPAEMA/P(3-TSPM)-1 JNPs at different $\mathrm{pH} 6.0$ and 10.0 values, which show very little or no interfacial activity (Table 1$)$.

The most surprising result is that the PS-PDIPAEMA/P(3TSPM)-1 JNPs show a measurable drop of the IFT also at the air-water interface. The dynamic IFT measurements of the JNP adsorption at the air-water interface at $\mathrm{pH} 2.0$ are given in Figure 5B. This is the long-sought proof that JNPs behave similarly to surfactants but with much slower adsorption kinetics at the air-water interfaces. The calculated interfacial attachment energy of the PS-PDIPAEMA/P(3-TSPM)-1JNPs at the airwater interface is $-7.2 \times 10^{-4} \mathrm{kT}$ with a JNP concentration of 10 $\mathrm{mg} / \mathrm{mL}$ at $\mathrm{pH} 2.0$, lower in magnitude than that at the Hepwater and Tol-water interfaces (Table 1). While the curves in Figure 5 did not achieve equilibrium at a long time, the values we have taken for $\gamma_{p}$ are asymptotically close to the equilibrium values of the IFT. We feel these values are the best values that we could obtain given the limitation of the experiment, especially at the air-water interface, which is limited by water evaporation from the pendant drop.

By comparing the PS-PDIPAEMA/P(3-TSPM)-1 JNP behavior for all of the interfaces investigated thus far, we arrive at the conclusion that these $\mathrm{pH}$-responsive PS-PDIPAEMA/ $\mathrm{P}$ (3-TSPM)-1 JNPs adsorb most readily at the Hep-water interface, followed by the Tol-water interface, and last at the air-water interface. But the reason why the equilibrium IFT is lowest for the Tol-water interface than for the Hep-water and air-water interfaces is because the JNPs prefer toluene. The affinity of the JNPs to toluene translates into a lower Tol-JNP interfacial energy than that for other solvents. After JNP interfacial adsorption, the magnitude of the IFT can be roughly regarded as the sum of the newly formed IFTs, Tol-JNP and water-JNP. Therefore, $\gamma_{\mathrm{p}}$ is the lowest because the JNPs have the lowest interfacial energy with toluene (i.e., lower Tol-JNP IFT) than with heptane or air, as we have discussed in a previous publication. ${ }^{5}$

The adsorption kinetics of particles at interfaces could be diffusion-controlled, energy-barrier-controlled, or a combination of the two. ${ }^{41,45,46}$ The adsorption kinetics of NPs measured via pendant-drop dynamic IFT measurements are typically modeled using the Ward and Tordai theory, ${ }^{47}$ which considers that adsorption is controlled by the particle's concentration and bulk diffusivity followed by instantaneous adsorption at the interface. However, in the presence of an energy barrier, the adsorption at the interface is much slower than that assumed by the purely diffusive model. In order to account for an activation energy barrier in interfacial adsorption, Liggieri et al. $^{45}$ and Ravera et al. ${ }^{46}$ proposed the effective diffusion model. This enables calculation of the activation energy barrier from the observed effective diffusion coefficient from the dynamic IFT measurement, typically much lower than the Stokes-Einstein diffusivity if an energy barrier is present. In order to calculate the magnitude of the energy barrier for PS-PDIPAEMA/P(3-TSPM)-1 JNPs' interfacial adsorption, we first calculated the effective diffusion coefficient using the following equation used by Dugyala et al. ${ }^{41}$ for the same purpose:

$$
\gamma=\gamma_{0}-2 N_{\mathrm{A}} C_{0} \Delta E \sqrt{\frac{D_{\mathrm{eff}} t}{\pi}}
$$

where $C_{0}$ is the concentration of the particles in bulk, $\gamma_{0}$ the surface tension of the clean interface, $\Delta E$ the attachment energy (here calculated in Table 1 ), and $D_{\text {eff }}$ the effective diffusion coefficient. By fitting the earlier portion of the IFT versus $\sqrt{t}$ 
Table 2. Activation Energies of the Attachment of the PS-PDIPAEMA/P(3-TSPM)-1 JNPs and PS-PDIPAEMA-2 NPs at TolWater, Hep-Water, and Air-Water Interfaces and Their Diffusivities, Effective versus Actual

\begin{tabular}{|c|c|c|c|c|c|}
\hline interface & $D_{0}^{a}\left(\mathrm{~m}^{2} / \mathrm{s}\right)$ & $D_{\text {eff }}^{b}\left(\mathrm{~m}^{2} / \mathrm{s}\right)$ & $E_{\mathrm{a}}\left(\mathrm{k}_{\mathrm{B}} \mathrm{T}\right)$ & slope $^{c}$ & $\Delta E\left(\mathrm{k}_{\mathrm{B}} \mathrm{T}\right)$ \\
\hline JNPs/Tol-water & $1.65 \times 10^{-12}$ & $5.41 \times 10^{-15}$ & 5.8 & -0.45 & $-2.2 \times 10^{5}$ \\
\hline JNPs/Hep-water & $1.65 \times 10^{-12}$ & $6.24 \times 10^{-15}$ & 5.6 & -0.63 & $-2.9 \times 10^{5}$ \\
\hline JNPs/air-water & $1.65 \times 10^{-12}$ & $1.47 \times 10^{-15}$ & 7.1 & -0.08 & $-7.2 \times 10^{4}$ \\
\hline PS-PDIPAEMA-2/Tol-water & $4.94 \times 10^{-12}$ & $3.39 \times 10^{-15}$ & 7.3 & -0.05 & $-3.0 \times 10^{4}$ \\
\hline PS-PDIPAEMA-2/Hep-water & $4.94 \times 10^{-12}$ & $1.23 \times 10^{-14}$ & 6.0 & -0.21 & $-6.9 \times 10^{4}$ \\
\hline PS-PDIPAEMA-2/air-water & $4.94 \times 10^{-12}$ & $1.83 \times 10^{-15}$ & 8.0 & -0.06 & $-2.0 \times 10^{4}$ \\
\hline
\end{tabular}

${ }^{a}$ Calculated using eq $3 .{ }^{b}$ Calculated using eq $2 .{ }^{c}$ From the curves in Figure S8.

curves, where $t \leq 180 \mathrm{~s}$ at all interfaces and a bulk concentration of $10 \mathrm{mg} / \mathrm{mL}$ (Figure S8), we were able to extract the values of $D_{\text {eff }}$ corresponding to all interfaces. Fitting the earlier portion of the curves is justified by the fact that the incoming particles meet a pristine interface; at a later time, the electrostatic repulsion between the adsorbed and incoming particles dominates. ${ }^{41}$ The results obtained for the JNP diffusivity $D_{\text {eff }}$ are given in Table 2 . From this, it can be observed that $D_{\text {eff }}$ changes significantly for the data at each interface, which is indicative that interfacial adsorption of the PS-PDIPAEMA/P(3-TSPM)-1 JNPs is not purely diffusion-controlled but the activation energy to the attachment at each interface plays a role. The obtained effective diffusion coefficient $D_{\text {eff }}$ can be compared with the ones calculated from the Stokes-Einstein equation, i.e.,

$$
D_{0}=\frac{k_{\mathrm{B}} T}{6 \pi \mu R}
$$

where $\mu$ is the viscosity of water and $R$ is the radius of the NPs. The diffusivity results obtained from these calculations for each $\mathrm{NP}$ are given in Table 2. When $D_{\text {eff }}$ is compared to $D_{0}$, it becomes obvious that the values taken by the former are 1 or 2 orders of magnitude lower than those of the latter; therefore, an activation energy barrier for the attachment of NPs at the interface must be considered. For comparison, applying the same treatment, Basavaraj et al. ${ }^{41}$ obtained differences between $D_{\text {eff }}$ versus $D_{0}$ as large as 3 orders of magnitude for $10 \mathrm{~nm}$ silica particles (significantly smaller than those used here) at the dodecanewater interface. Noting these differences, it follows that the activation energy for the attachment can be further calculated from the equation

$$
D_{\text {eff }}=D_{0} \exp \left(-\frac{E_{\mathrm{a}}}{k_{\mathrm{B}} T}\right)
$$

where $E_{\mathrm{a}}$ is the activation energy of the attachment at the interface. The effective diffusion coefficient obtained from eq 2 is 3 orders of magnitude lower in all cases than the actual diffusion coefficient calculated with eq 3 (Table 2). This can only be explained by the existence of an activation energy barrier that can be calculated with eq 4 . The calculated $E_{a}$ from eq 4 for the adsorption of PS-PDIPAEMA/P(3-TSPM)-1 JNPs at each interface are summarized in Table 2 . It can be observed that the largest $E_{\mathrm{a}}$ corresponds to the air-water interface $(7.1 \mathrm{kT})$, followed by the Tol-water $(5.8 \mathrm{kT})$ and Hep-water $(5.6 \mathrm{kT})$ interfaces. Interestingly, the energy barrier only differs slightly between the Tol-water and Hep-water interfaces. Our observations show that the air-water interface is only slightly "attractive" to the positively charged PS-PDIPAEMA/P(3TSPM)-1 JNPs at $\mathrm{pH}$ 2.0. If interfacial adsorption has an electrostatic origin, there could be an interaction between the air-water and solvent-water interfaces that are negatively charged, $^{48}$ with the PS-PDIPAEMA/P(3-TSPM)-1 JNPs positively charged at $\mathrm{pH} 2.0$. To explain the difference in the activation energies for adsorption, one could compare the charge density of the air-water interface in a $0.2 \mathrm{mM} \mathrm{NaCl}$ electrolyte, which is $-0.25 \mu \mathrm{C} / \mathrm{cm}^{2}$, about half that of the hexane-water interface $\left(-0.6 \mu \mathrm{C} / \mathrm{cm}^{2}\right)$ in the presence of a $0.3 \mathrm{mM}$ electrolyte, according to the data summarized by Warr et al. ${ }^{49}$ This difference could provide an explanation as to why the observed activation energy of adsorption of JNPs to the Hep-water interface is lower than that to the air-water interface. Recently, several publications report spontaneous adsorption of various HNPs at the interfaces of water and organic solvents and without external energy input. ${ }^{21,50,51}$ It has also been suggested that softness could be the primary factor that drives the spontaneous adsorption of NPs at interfaces; for example, $\mathrm{Xu}$ et al. ${ }^{20}$ synthesized soft poly (N-isopropylacrylamide)-polystyrene (PNIPAM-PS) NPs; the softness was controlled by the amount of styrene used during polymerization of the synthesis of NPs. The authors have found that at $25{ }^{\circ} \mathrm{C}$ the soft PNIPAM-PS NPs can reduce the Hep-water IFT from 50 to $10 \mathrm{mN} / \mathrm{m}$, while the harder PNIPAM-PS NPs were only able to reduce the Hep-water IFT from 50 to $40 \mathrm{mN} / \mathrm{m}$ at the same concentration. Other parameters of the particles that may influence the spontaneous adsorption of particles at the interface include the surface energy, ${ }^{52}$ shape, ${ }^{53}$ etc. $^{54}$

It is also likely that the activation energy barrier to particle adsorption is the result of energy costs related to surface dehydration of the JNPs initially in water and surface resolvation by the solvent in the second phase (see the cartoon in Figure 6). In such a case, then the better wetting solvent should have the lowest activation energy, in this case heptane. Although in the cartoon of Figure 6 we have not implied any preferred orientation nor a particular interfacial immersion depth of the JNPs, we believe that the activation energy is also affected by these parameters. The magnitude of $E_{\mathrm{a}}$ is determined by the relative hydrated versus solvated areas of the two liquid phases. For example, if the orientation of the JNPs is such that it decreases the wetted area (the long axis fully perpendicular to the interface vs long axis flat at the interface), the dehydrated area upon interfacial adsorption and the activation energy would also be lower. The PS-PDIPAEMA-2 HNPs have larger activation energy barriers than the JNPs at the corresponding interfaces (Table 2). The PS-PDIPAEMA-2 HNPs are smaller and softer at $\mathrm{pH} 2.0$, and if the softness factor would be the preferred mechanism of adsorption, then one would expect these to have lower activation energies than the PS-PDIPAEMA/P(3TSPM)-1 JNPs, which have, in addition, a "harder" $\mathrm{P}$ (3TSPM) lobe. Therefore, one could dismiss the particle "softness" as the only parameter for particle interfacial adsorption and must also consider the amphiphilicity. An effective diffusion coefficient and thus energy barrier could not be calculated for particles that 


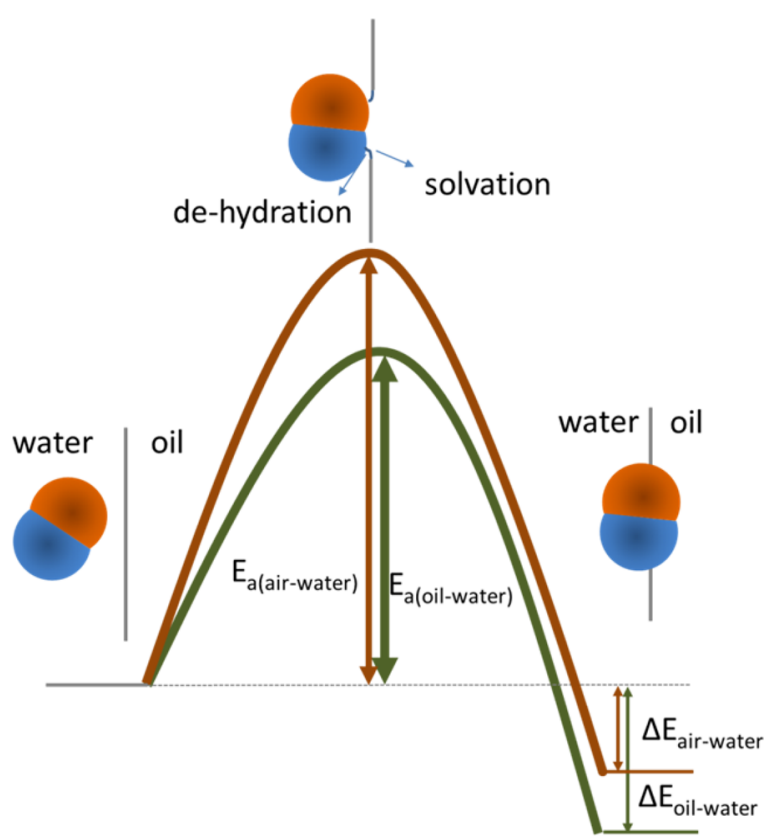

Figure 6. Cartoon depicting the attachment energy $\Delta E$ and the activation energy $E_{\mathrm{a}}$ for interfacial adsorption of the PS-PDIPAEMA/ P(3-TSPM)-1 JNPs at the oil-water and air-water interfaces. Note that the cartoon does not imply a preferred orientation for JNPs at the interfaces.

now show the interfacial activity, which implies that the energy barrier for the surface attachment is very large. Here we provided the first evidence that JNP amphiphiles do adsorb spontaneously at the interfaces and are at least 3 times more interfacially active than the HNPs from the same materials as the lobes. Even more, their amphiphilicity and interfacial activity can be switched off at $\mathrm{pH} 6.0$ and 10.0 and switched back on at $\mathrm{pH}$ 2.0.

3.5. Scanning Electron Microscopy (SEM) of PSPDIPAEMA/P(3-TSPM)-1 JNPs at the Wax-Water Interface. The pendant-drop results in the last section show the IFT decreasing because of the adsorption of particles at the interface; moreover, $\triangle$ IFT depends on the JNPs' bulk concentration in the aqueous solution. Furthermore, a plateau is reached, and the IFT does not decrease anymore at long times above NP concentrations of $10 \mathrm{mg} / \mathrm{mL}$, meaning that the interface is fully saturated with JNPs. In order to prove that JNPs do adsorb at the interface and that their density at the interface depends on their bulk concentration, we have studied the interfacial adsorption with SEM at the molten wax (mp $\left.55{ }^{\circ} \mathrm{C}\right)$-water interface. After sufficient time was allowed for particle adsorption (15 min) for four different PS-PDIPAEMA/P(3-TSPM)-1 JNPs with different concentrations $(10,1$, and $0.1 \mathrm{mg} / \mathrm{mL})$ at different $\mathrm{pH}$ values $\left(\mathrm{pH} 2.0\right.$ and 10.0) at $70{ }^{\circ} \mathrm{C}$, the wax was allowed to slowly cool to room temperature and solidify. After solidification, the wax surface was removed from the aqueous solution and allowed to dry without any further rinsing or handling. In this way, the JNPs present at the interface remained trapped, and their surface density was estimated from the SEM images, as presented in Figure S9. We emphasize here that this system is not ideal and not perfectly equivalent to the Hep-water interface, as the interfacial adsorption experiments are performed at $70{ }^{\circ} \mathrm{C}$. However, a qualitative trend can be observed, and from the images in Figure S9, coverage of the PS-PDIPAEMA/P(3TSPM)-1 JNPs at the interface significantly decreases with a decrease in the bulk concentration as expected. At $\mathrm{pH}$ 2.0, we can clearly see that the PS-PDIPAEMA/P(3-TSPM)-1 JNPs are present at the interface as individual particles but are also assembled into islands; moreover, the surface densities of the PS-PDIPAEMA/P(3-TSPM)-1 JNPs at the wax-water interface increased with increasing concentration from 0.1 to $10 \mathrm{mg} /$ $\mathrm{mL}$ (Figure S9A-C). At $\mathrm{pH} \mathrm{10.0,} \mathrm{the} \mathrm{densities} \mathrm{of} \mathrm{the} \mathrm{PS-}$ PDIPAEMA/P(3-TSPM)-1 JNPs at the wax-water interface are extremely low (Figure S9D), proving that these are not interfacially active at this $\mathrm{pH}$ and also excluding the possibility that the PS-PDIPAEMA/P(3-TSPM)-1 JNPs could adsorb at the Tol-water and Hep-water interfaces without producing a change in the IFT. Interestingly, these islands appear to be more than one monolayer thick in some cases; it is, however, possible that these particles may have attached during removal of the sample from the water solution. Similarly, it is not clear if the interfacially adsorbed PS-PDIPAEMA/P(3-TSPM)-1 JNPs self-assemble into islands or these are formed as a consequence of fluctuations at the wax-water interface upon cooling and solidification. Therefore, we emphasize that these are only given for qualitative evaluation for the number density increase of the PS-PDIPAEMA/P(3-TSPM)-1 JNPs at the interface with the bulk concentration and as proof that indeed there is significant adsorption of the JNPs at the oil-water interface. Also, no orientation of the PS-PDIPAEMA/P(3-TSPM)-1 JNPs at the wax-water interface could be identified with this method, but this possibility cannot be entirely dismissed.

\section{CONCLUSIONS}

We have designed and synthesized PS-PDIPAEMA/P(3TSPM)-1 JNPs pH-responsive JNPs that can spontaneously adsorb at the oil-water and, more importantly, air-water interfaces and produce a detectable change in the IFT. We provided direct evidence that JNPs are up to 3 times (by comparing the $\Delta$ IFTs) and between 3 and 7 times (by comparing $\Delta E$ ) more interfacially active than the corresponding HNPs, with the same surface properties and comparable sizes to each of the constituting Janus lobes. These observed differences, which are even larger than the earlier theoretical predictions, ${ }^{34}$ prove that indeed the amphiphilicity plays a role in enhancement of the interfacial activity of JNPs versus HNPs even at the 100$200 \mathrm{~nm}$ scale. The largest activation energy of the attachment corresponds to the air-water interface, while the lowest corresponds to the Tol-water interface. We attribute these differences to the dehydration-resolvation processes that accompany the interfacial adsorption process. In this scenario, it is expected that the activation energy barrier of JNP and HNP adsorption at the air-water interface is the largest compared with the Tol-water and Hep-water interfaces because the overall energy cost for surface dehydration is not compensated for by surface "resolvation" by the solvent in the second phase. Furthermore, the activation energy of the interfacial attachment is consistently larger for HNPs than for JNPs at all three kinds of tested interfaces. We have thus shown that the PS-PDIPAEMA/ $\mathrm{P}$ (3-TSPM) -1 JNPs $\mathrm{pH}$-responsive JNPs are superior to the HNPs in terms of the interfacial activity, and this is especially important for interfacial applications such as the stabilization of Pickering emulsions and energy input required to produce them. Given the excellent interfacial activity of the PS-PDIPAEMA/ $\mathrm{P}$ (3-TSPM)-1 JNPs, further work should be focused on their ability to function as "bulk-to-interface" carriers of different small molecules or could be deployed in toxic or precious metal-cation recovery, extraction from wastewaters, and hydrological mining applications. Future work could be aimed toward investigating 
the relationship between the Pickering emulsion properties and stability as a function of the size ratio of the hydrophobic and hydrophilic domains in JNPs, particle symmetry, and size.

\section{ASSOCIATED CONTENT}

\section{S Supporting Information}

The Supporting Information is available free of charge on the ACS Publications website at DOI: 10.1021/acsanm.7b00356.

Experimental methods, including synthesis of NPs, Pickering emulsion characterization, and interfacial tension measurements, results, including particle properties, SEM images of the NPs, tables with NP and JNP compositions and diameters, FTIR spectra of JNPs and NPs, DLS-determined diameters of the seed NPs with $\mathrm{pH}$, DLS-determined diameters and $\zeta$ potential of the JNPs with $\mathrm{pH}$, and emulsification results, influence of the ionic strength on the emulsion phase, effective diffusion model fits, and SEM image of JNP adsorption at the wax-water interface as a function of the concentration and $\mathrm{pH}$ (PDF)

\section{AUTHOR INFORMATION}

\section{Corresponding Author}

*E-mail: andrei.honciuc@zhaw.ch. Tel.: +41589345283.

\section{ORCID}

Andrei Honciuc: 0000-0003-2160-2484

Notes

The authors declare no competing financial interest.

\section{ACKNOWLEDGMENTS}

We are especially grateful for the financial support of Metrohm Foundation (Herisau, Switzerland).

\section{REFERENCES}

(1) Wu, D.; Chew, J. W.; Honciuc, A. Polarity Reversal in Homologous Series of Surfactant-Free Janus Nanoparticles: Toward the Next Generation of Amphiphiles. Langmuir 2016, 32 (25), 6376-6386.

(2) Casagrande, C.; Fabre, P.; Raphaël, E.; Veyssié, M. Janus Beads": Realization and Behaviour at Water/Oil Interfaces. EPL Europhys. Lett. 1989, 9 (3), 251-255.

(3) Walther, A.; Müller, A. H. E. Janus Particles: Synthesis, SelfAssembly, Physical Properties, and Applications. Chem. Rev. 2013, 113 (7), 5194-5261.

(4) de Gennes, P. G. Soft Matter. Rev. Mod. Phys. 1992, 64 (3), 645648.

(5) Wu, D.; Binks, B. P.; Honciuc, A. Modeling the Interfacial Energy of Surfactant-Free Amphiphilic Janus Nanoparticles from Phase Inversion in Pickering Emulsions. Langmuir 2017, DOI: 10.1021/ acs.langmuir.7b02331.

(6) Xue, W.; Yang, H.; Du, Z. Synthesis of pH-Responsive Inorganic Janus Nanoparticles and Experimental Investigation of the Stability of Their Pickering Emulsions. Langmuir 2017, 33 (39), 10283-10290.

(7) Fujii, S.; Yokoyama, Y.; Nakayama, S.; Ito, M.; Yusa, S.; Nakamura, Y. Gas Bubbles Stabilized by Janus Particles with Varying HydrophilicHydrophobic Surface Characteristics. Langmuir 2017, DOI: 10.1021/ acs.langmuir.7b02670.

(8) Yan, J.; Chaudhary, K.; Chul Bae, S.; Lewis, J. A.; Granick, S. Colloidal Ribbons and Rings from Janus Magnetic Rods. Nat. Commun. 2013, 4, 1516.

(9) Gröschel, A. H.; Müller, A. H. E. Self-Assembly Concepts for Multicompartment Nanostructures. Nanoscale 2015, 7 (28), 1184111876.

(10) Tu, F.; Lee, D. Shape-Changing and Amphiphilicity-Reversing Janus Particles with pH-Responsive Surfactant Properties. J. Am. Chem. Soc. 2014, 136 (28), 9999-10006.
(11) Bradley, L. C.; Stebe, K. J.; Lee, D. Clickable Janus Particles. J. Am. Chem. Soc. 2016, 138 (36), 11437-11440.

(12) Song, J.; Wu, B.; Zhou, Z.; Zhu, G.; Liu, Y.; Yang, Z.; Lin, L.; Yu, G.; Zhang, F.; Zhang, G.; Duan, H.; Stucky, G. D.; Chen, X. DoubleLayered Plasmonic-Magnetic Vesicles by Self-Assembly of Janus Amphiphilic Gold-Iron(II,III) Oxide Nanoparticles. Angew. Chem., Int. Ed. 2017, 56 (28), 8110-8114.

(13) Jiang, S.; Chen, Q.; Tripathy, M.; Luijten, E.; Schweizer, K. S.; Granick, S. Janus Particle Synthesis and Assembly. Adv. Mater. 2010, 22 (10), 1060-1071.

(14) Noguchi, T. G.; Iwashita, Y.; Kimura, Y. Dependence of the Internal Structure on Water/Particle Volume Ratio in an Amphiphilic Janus Particle-Water-Oil Ternary System: From Micelle-like Clusters to Emulsions of Spherical Droplets. Langmuir 2017, 33 (4), 1030-1036.

(15) Binks, B. P.; Fletcher, P. D. I. Particles Adsorbed at the Oil-Water Interface: A Theoretical Comparison between Spheres of Uniform Wettability and "Janus" Particles. Langmuir 2001, 17 (16), 4708-4710.

(16) Aveyard, R. Can Janus Particles Give Thermodynamically Stable Pickering Emulsions? Soft Matter 2012, 8 (19), 5233-5240.

(17) Ruhland, T. M.; Gröschel, A. H.; Ballard, N.; Skelhon, T. S.; Walther, A.; Müller, A. H. E.; Bon, S. A. F. Influence of Janus Particle Shape on Their Interfacial Behavior at Liquid-Liquid Interfaces. Langmuir 2013, 29 (5), 1388-1394.

(18) Fernandez-Rodriguez, M. A.; Chen, L.; Deming, C. P.; RodriguezValverde, M. A.; Chen, S.; Cabrerizo-Vilchez, M. A.; Hidalgo-Alvarez, R. A Simple Strategy to Improve the Interfacial Activity of True Janus Gold Nanoparticles: A Shorter Hydrophilic Capping Ligand. Soft Matter 2016, 12 (1), 31-34.

(19) Fernandez-Rodriguez, M. A.; Ramos, J.; Isa, L.; RodriguezValverde, M. A.; Cabrerizo-Vilchez, M. A.; Hidalgo-Alvarez, R. Interfacial Activity and Contact Angle of Homogeneous, Functionalized, and Janus Nanoparticles at the Water/Decane Interface. Langmuir 2015, 31 (32), 8818-8823.

(20) Li, Z.; Harbottle, D.; Pensini, E.; Ngai, T.; Richtering, W.; Xu, Z. Fundamental Study of Emulsions Stabilized by Soft and Rigid Particles. Langmuir 2015, 31 (23), 6282-6288.

(21) Richtering, W. Responsive Emulsions Stabilized by StimuliSensitive Microgels: Emulsions with Special Non-Pickering Properties. Langmuir 2012, 28 (50), 17218-17229.

(22) Fernandez-Rodriguez, M. A.; Song, Y.; Rodríguez-Valverde, M. Á.; Chen, S.; Cabrerizo-Vilchez, M. A.; Hidalgo-Alvarez, R. Comparison of the Interfacial Activity between Homogeneous and Janus Gold Nanoparticles by Pendant Drop Tensiometry. Langmuir 2014, 30 (7), $1799-1804$.

(23) Ravera, F.; Ferrari, M.; Liggieri, L.; Loglio, G.; Santini, E.; Zanobini, A. Liquid-liquid Interfacial Properties of Mixed Nanoparticle-surfactant Systems. Colloids Surf., A 2008, 323 (1), 99-108.

(24) Wu, J.; Ma, G.-H. Recent Studies of Pickering Emulsions: Particles Make the Difference. Small 2016, 12 (34), 4633-4648.

(25) Xie, H.; She, Z.-G.; Wang, S.; Sharma, G.; Smith, J. W. One-Step Fabrication of Polymeric Janus Nanoparticles for Drug Delivery. Langmuir 2012, 28 (9), 4459-4463.

(26) Yang, H.; Zhou, T.; Zhang, W. A Strategy for Separating and Recycling Solid Catalysts Based on the pH-Triggered PickeringEmulsion Inversion. Angew. Chem., Int. Ed. 2013, 52 (29), 7455-7459.

(27) Huang, J.; Yang, H. A pH-Switched Pickering Emulsion Catalytic System: High Reaction Efficiency and Facile Catalyst Recycling. Chem. Commun. 2015, 51 (34), 7333-7336.

(28) Huang, J.; Cheng, F.; Binks, B. P.; Yang, H. pH-Responsive GasWater-Solid Interface for Multiphase Catalysis. J. Am. Chem. Soc. 2015, 137 (47), 15015-15025.

(29) Bories-Azeau, X.; Armes, S. P.; van den Haak, H. J. W. Facile Synthesis of Zwitterionic Diblock Copolymers without Protecting Group Chemistry. Macromolecules 2004, 37 (7), 2348-2352.

(30) Fonseca, T.; Relógio, P.; Martinho, J. M. G.; Farinha, J. P. S. Preparation and Surface Characterization of Polymer Nanoparticles Designed for Incorporation into Hybrid Materials. Langmuir 2007, 23 (10), 5727-5734. 
(31) Finkle, P.; Draper, H. D.; Hildebrand, J. H. THE THEORY OF EMULSIFICATION1. J. Am. Chem. Soc. 1923, 45 (12), 2780-2788.

(32) Bancroft, W. D. Applied Colloid Chemistry; General Theory; International Chemical Series; McGraw-Hill Book Company, Inc.: New York, 1921.

(33) Kumar, A.; Li, S.; Cheng, C.-M.; Lee, D. Recent Developments in Phase Inversion Emulsification. Ind. Eng. Chem. Res. 2015, 54 (34), 8375-8396.

(34) Binks, B. P.; Fletcher, P. D. I. Particles Adsorbed at the Oil-Water Interface: A Theoretical Comparison between Spheres of Uniform Wettability and "Janus" Particles. Langmuir 2001, 17 (16), 4708-4710.

(35) Destribats, M.; Lapeyre, V.; Wolfs, M.; Sellier, E.; Leal-Calderon, F.; Ravaine, V.; Schmitt, V. Soft Microgels as Pickering Emulsion Stabilisers: Role of Particle Deformability. Soft Matter 2011, 7 (17), 7689-7698.

(36) Destribats, M.; Lapeyre, V.; Sellier, E.; Leal-Calderon, F.; Ravaine, V.; Schmitt, V. Origin and Control of Adhesion between Emulsion Drops Stabilized by Thermally Sensitive Soft Colloidal Particles. Langmuir 2012, 28 (8), 3744-3755.

(37) Fujii, S.; Read, E. S.; Binks, B. P.; Armes, S. P. StimulusResponsive Emulsifiers Based on Nanocomposite Microgel Particles. Adv. Mater. 2005, 17 (8), 1014-1018.

(38) Deshmukh, O. S.; van den Ende, D.; Stuart, M. C.; Mugele, F.; Duits, M. H. G. Hard and Soft Colloids at Fluid Interfaces: Adsorption, Interactions, Assembly \& Rheology. Adv. Colloid Interface Sci. 2015, 222, 215-227.

(39) Shrestha, A.; Bohinc, K.; May, S. Immersion Depth of Positively versus Negatively Charged Nanoparticles at the Air-Water Interface: A Poisson-Boltzmann Model. Langmuir 2012, 28 (40), 14301-14307.

(40) Kettlewell, S. L.; Schmid, A.; Fujii, S.; Dupin, D.; Armes, S. P. Is Latex Surface Charge an Important Parameter for Foam Stabilization? Langmuir 2007, 23 (23), 11381-11386.

(41) Dugyala, V. R.; Muthukuru, J. S.; Mani, E.; Basavaraj, M. G. Role of Electrostatic Interactions in the Adsorption Kinetics of Nanoparticles at Fluid-fluid Interfaces. Phys. Chem. Chem. Phys. 2016, 18 (7), 54995508.

(42) Garbin, V.; Crocker, J. C.; Stebe, K. J. Nanoparticles at Fluid Interfaces: Exploiting Capping Ligands to Control Adsorption, Stability and Dynamics. J. Colloid Interface Sci. 2012, 387 (1), 1-11.

(43) Glaser, N.; Adams, D. J.; Böker, A.; Krausch, G. Janus Particles at Liquid-Liquid Interfaces. Langmuir 2006, 22 (12), 5227-5229.

(44) Du, K.; Glogowski, E.; Emrick, T.; Russell, T. P.; Dinsmore, A. D. Adsorption Energy of Nano- and Microparticles at Liquid-Liquid Interfaces. Langmuir 2010, 26 (15), 12518-12522.

(45) Liggieri, L.; Ravera, F.; Passerone, A. A Diffusion-Based Approach to Mixed Adsorption Kinetics. Colloids Surf., A 1996, 114, 351-359.

(46) Ravera, F.; Liggieri, L.; Steinchen, A. Sorption Kinetics Considered as a Renormalized Diffusion Process. J. Colloid Interface Sci. 1993, 156 (1), 109-116.

(47) Ward, A. F. H.; Tordai, L. Time-Dependence of Boundary Tensions of Solutions I. The Role of Diffusion in Time-Effects. J. Chem. Phys. 1946, 14 (7), 453-461.

(48) Roger, K.; Cabane, B. Why Are Hydrophobic/Water Interfaces Negatively Charged? Angew. Chem., Int. Ed. 2012, 51 (23), 5625-5628.

(49) Beattie, J. K.; Djerdjev, A. M.; Warr, G. G. The Surface of Neat Water Is Basic. Faraday Discuss. 2009, 141, 31-39.

(50) Manga, M. S.; Hunter, T. N.; Cayre, O. J.; York, D. W.; Reichert, M. D.; Anna, S. L.; Walker, L. M.; Williams, R. A.; Biggs, S. R. Measurements of Submicron Particle Adsorption and Particle Film Elasticity at Oil-Water Interfaces. Langmuir 2016, 32 (17), 4125-4133.

(51) Bizmark, N.; Ioannidis, M. A. Effects of Ionic Strength on the Colloidal Stability and Interfacial Assembly of Hydrophobic Ethyl Cellulose Nanoparticles. Langmuir 2015, 31 (34), 9282-9289.

(52) Alvarez, N. J.; Anna, S. L.; Saigal, T.; Tilton, R. D.; Walker, L. M. Interfacial Dynamics and Rheology of Polymer-Grafted Nanoparticles at Air-Water and Xylene-Water Interfaces. Langmuir 2012, 28 (21), 8052-8063.

(53) Davies, G. B.; Krüger, T.; Coveney, P. V.; Harting, J.; Bresme, F. Interface Deformations Affect the Orientation Transition of Magnetic
Ellipsoidal Particles Adsorbed at Fluid-fluid Interfaces. Soft Matter 2014, 10 (35), 6742-6748.

(54) Bresme, F.; Oettel, M. Nanoparticles at Fluid Interfaces. J. Phys.: Condens. Matter 2007, 19 (41), 413101-413133. 